\title{
Immediate loading in edentulous maxilla - a case report
}

\author{
Terapia implantară cu protezare imediată maxilară - Prezentare de caz
}

Bogdan Mihai Gălbinaşu, Veronica Bucur, Ion Pătraşcu
Catedra de Tehnologia Protezelor şi Materiale Dentare, Facultatea de Medicină Dentară,
Universitatea de Medicină şi Farmacie „Carol Davila“, Bucureşti, România

\begin{abstract}
The main objective of inserting dental implants in various clinical situations is to avoid mobile prosthetic restorations or to obtain a better stability. In this way, patients are offered increased comfort and better integration of prosthetic restorations into the stomatognathic complex. The purpose of this case presentation is to highlight a case of complex oral rehabilitation in which the Sky Fast and Fixed system (Bredent $\mathrm{GmbH}$, Senden, Germany) was chosen, in the case of maxillary restoration, thus avoiding a mobile prosthetic restoration. The result demonstrates a superior aesthetic rehabilitation than the initial situation, obtaining a significant improvement from the first treatment session.
\end{abstract}

Keywords: implant, maxilla, fast and fixed, immediate loading, primary stability

\section{REZUMAT}

Obiectivul inserării implanturilor dentare în diverse situaţii clinice este acela de a evita restaurările protetice mobile sau de a obţine o mai bună stabilitate a acestora. În acest mod, li se oferă pacienţilor un confort sporit şi o mai bună integrare a restaurărilor protetice în complexul stomatognat. Scopul acestei prezentări de caz este de a evidenția un caz de reabilitare orală complexă în care s-a optat pentru sistemul Sky Fast and Fixed (Bredent GmbH, Senden, Germany) în cazul restaurării maxilare, evitând astfel o restaurare protetică mobilă. Rezultatul demonstrează o reabilitare estetică superioară situaţiei iniţiale, obţinându-se o îmbunătăţire semnificativă de la prima şedinţă de tratament.

Cuvinte cheie: implant, maxilar, fast and fixed, încărcare imediată, stabilitate primară

\section{INTRODUCERE}

Edentaţia totală reprezintă o situaţie clinică care implică o serie de disfuncţii ale întregului aparat stomatognat şi care se reflectă asupra întregului organism [1]. Pacienţii se pot prezenta în cabinetul stomatologic într-o astfel de stare de edentaţie sau cu un status dento-parodontal precar, indicându-se extracţia tuturor dinţilor restanţi. În această situaţie, există 2 direcţii de tratament: o restaurare protetică mobilă (proteză totală) sau o restaurare protetică ce va avea inclusă în etapele de tratament inserţia implanturilor dentare. În cea de-a doua situaţie, numărul şi topografia implanturilor împart tipurile de restaurări în: restaurare pro- tetică mobilizabilă (număr redus de implanturi pe care se vor ataşa sisteme speciale şi o supraproteză) [2] sau o restaurare protetică fixă. În ultimele decenii, terapiile ce presupun inserţia implanturilor dentare a cunoscut o tendinţă de a diminua atât timpii chirurgicali, cât şi cei de protezare a acestora. Aceasta abordare are în vedere un aspect legat de o reintegrare cât mai rapidă a pacientului, în plan fiziologic şi social $[3,4]$.

Astfel, a fost dezvoltat un concept ce presupune inserţia unui număr minim de implanturi (6 maxilar/4 mandibulă) $[5,6]$, ocolindu-se formaţiunile anatomice importante [7], şi utilizarea regiunilor alveolare, unde volumul osos permite inserţia implanturilor fără proceduri suplimentare de aug- 
mentare [8-13]. De asemenea, una dintre cerinţele clinice ale acestui sistem este ca implanturile să prezinte stabilitate primară astfel încât să permită protezarea imediată [14].

\section{PREZENTAREA CAZULUI}

Pacientul BC, în vârstă de 52 ani, s-a prezentat în cabinetul de stomatologie acuzând probleme de masticaţie şi fizionomie (Fig. 1, 2, 3, 4). Din punctul de vedere al stării de sănătate generală, pacientul a relatat anamnestic HTA grad 1 sub tratament medicamentos. În urma examinării clinice (Fig. 5) şi paraclinice (Fig. 6), i s-a explicat pacientului că necesită o reabilitare orală complexă şi i-au fost oferite mai multe variante de tratament. Pacientul şi-a exprimat dorinţa reabilitării cu restaurări fixe.

La examenul clinic, s-a observat prezenţa unor dinţi restanţi atât la maxilar, cât şi la mandibulă, cu un grad acccentuat de mobilitate dentară, 2 spre 3, şi a unor resturi radiculare irecuperabile. La examenul ATM, nu au fost observate modificări semnificative.

Examenul estetic a evidenţiat necesitatea restabilirii dimensiunii verticale de ocluzie, a curbelor de compensaţie, a culoarului neutral, a curbelor incizale şi bucale.
Pentru reabilitarea orală maxilară, s-a hotărât inserarea a 6 implanturi maxilare, optându-se pentru sistemul Sky Fast And Fix (Bredent GmbH, Senden, Germany) [6], ce presupune inserţia şi protezarea provizorie imediată. Pacientul a fost informat despre planul de tratament şi despre beneficiile unei restaurări protetice fixe imediate, fiind obţinut consimţământul acestuia.

Examenele paraclinice au fost completate de o analiză maxilară cu CBCT (Fig. 7). S-au realizat măsurătorile necesare şi au fost schiţaţi timpii chirurgicali şi protetici pentru o intervenţie optimă.

Procedura chirurgicală a început cu extracţia dinţilor restanţi. Au fost alese şi inserate 6 implanturi BlueSky, având de la dreapta la stânga următoarele dimensiuni: $4,5 * 14,4 * 14,4 * 14,4 * 14$, $4 * 14,4 * 16$. Având în vedere că unul dintre dezideratele acestei proceduri este de a avea stabilitate primară pentru toate implanturile inserate, pentru primul implant din cadranul 1, deşi se optase pentru un implant de $4 * 16$, s-a ales intraoperator o dimensiune de 4,5*14, atingându-se astfel scopul propus. Toate implanturile au avut stabilitate primară. Pentru a putea avea o protezare imediată, la nivelul fiecărui implant s-au fixat bonturile de titan de tip multiunit cu diferite grade de angulaţie $\left(0^{\circ}\right.$, $17,5^{\circ}, 35^{\circ}$ ) la un torq de $25 \mathrm{Ncm}$. S-a practicat su-
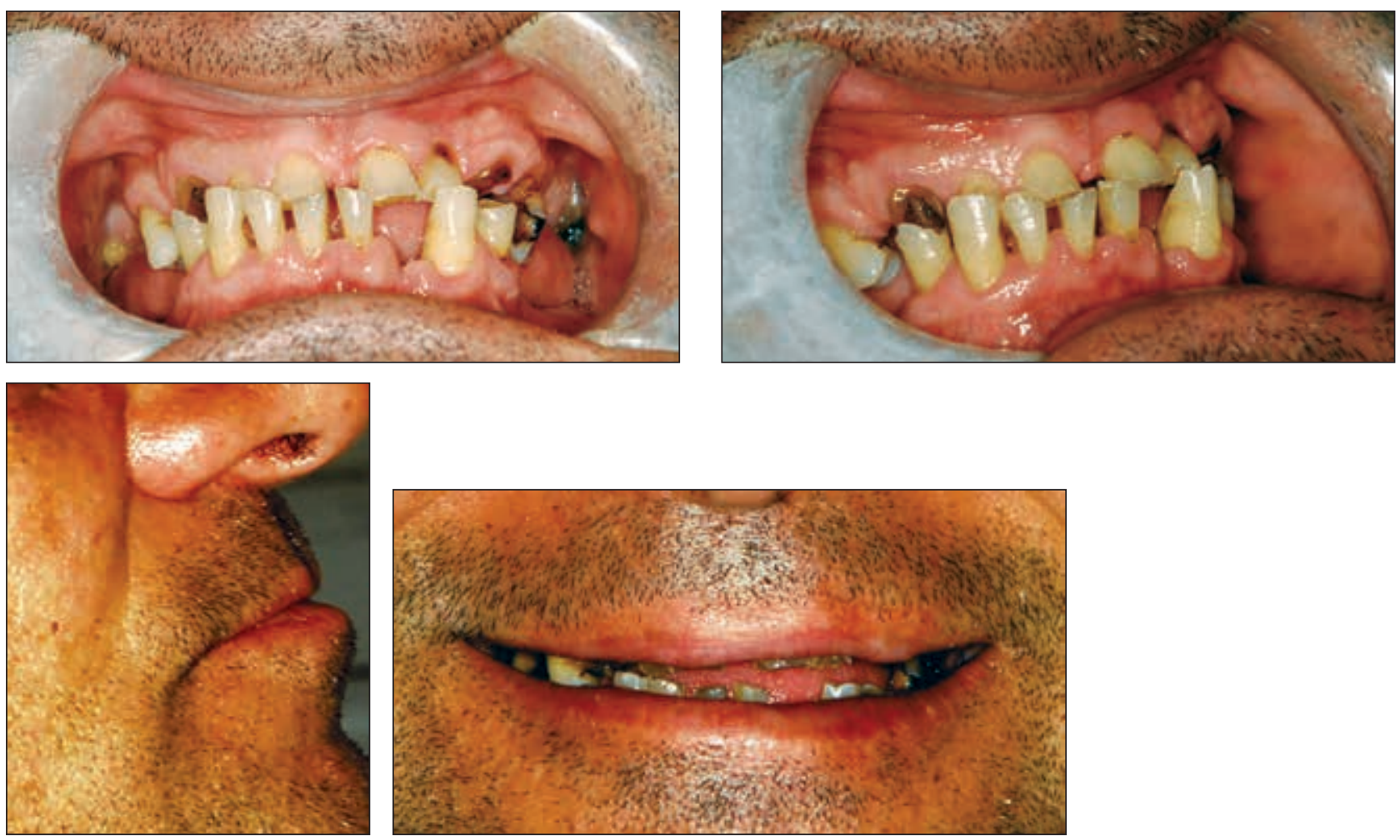

FIGURILE 1, 2, 3, 4. Imagini intra şi extraorale la prezentare 


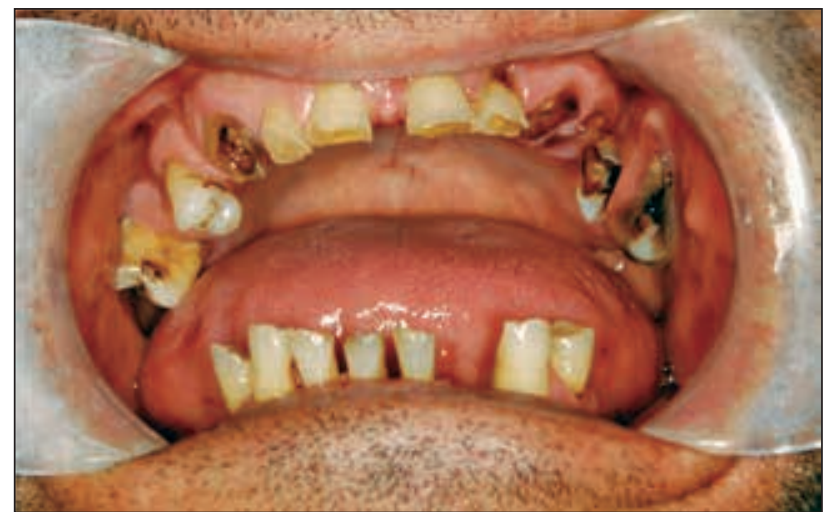

FIGURA 5. Examinare intraorală

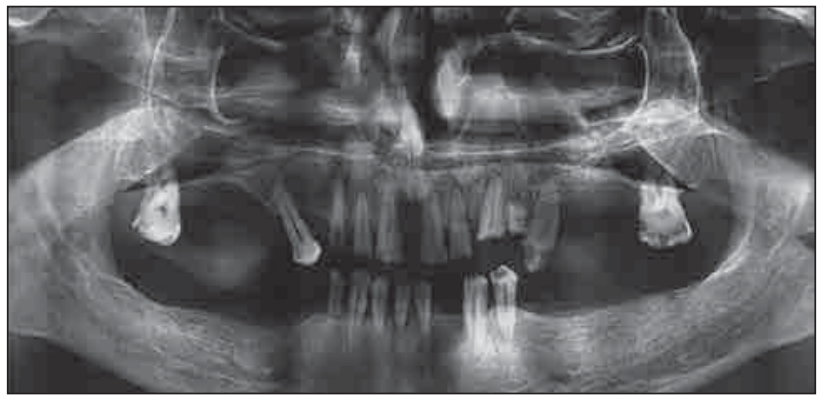

FIGURA 6. Examen radiologic

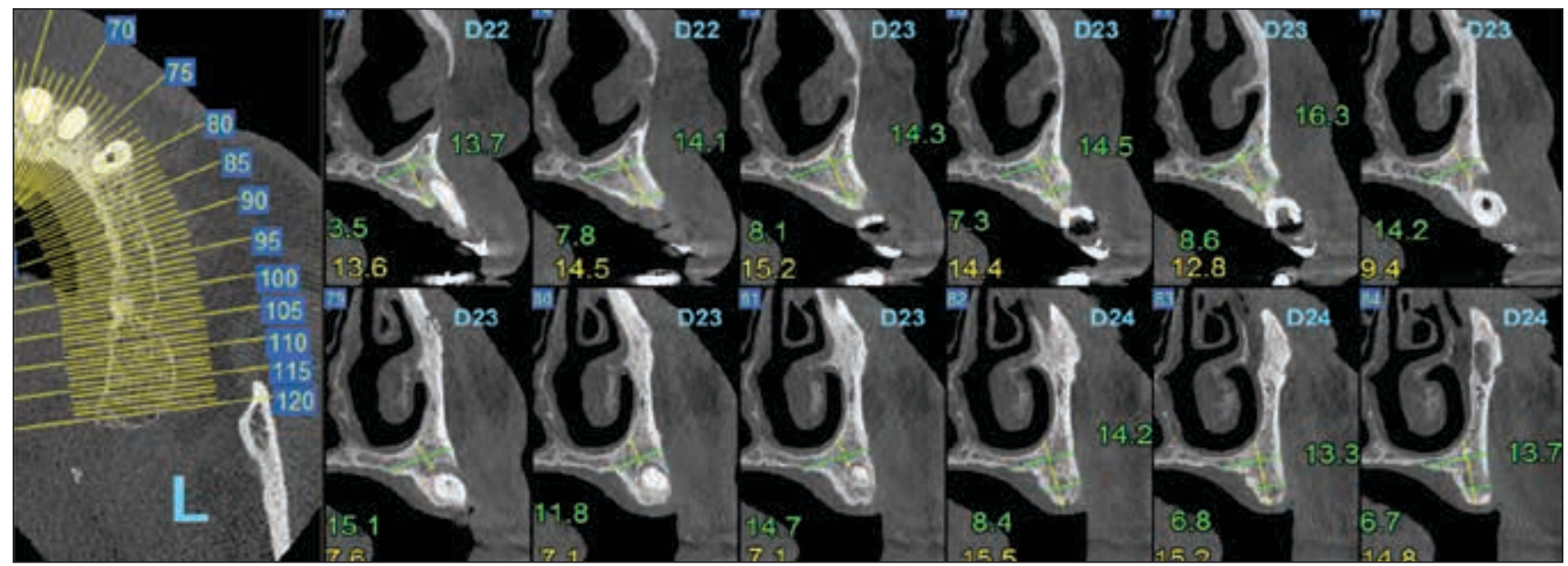

FIGURA 7. Examen CBCT

tură cu fire separate neresorbabile de tip poliamidă 5/0, urmând ca acestea să fie suprimate la un interval de 10 zile. Peste aceste bonturi a fost luată o amprentă cu lingură standard şi cu bonturile de transfer corespunzătoare. De asemenea, a fost înregistrată relaţia de ocluzie dintre maxilar şi mandibulă cu ajutorul unui silicon de ocluzie.

După această etapă chirurgicală, pacientului i s-a administrat medicaţie antibiotică şi antinflamatoare şi a fost lăsat să plece din cabinetul stomato-

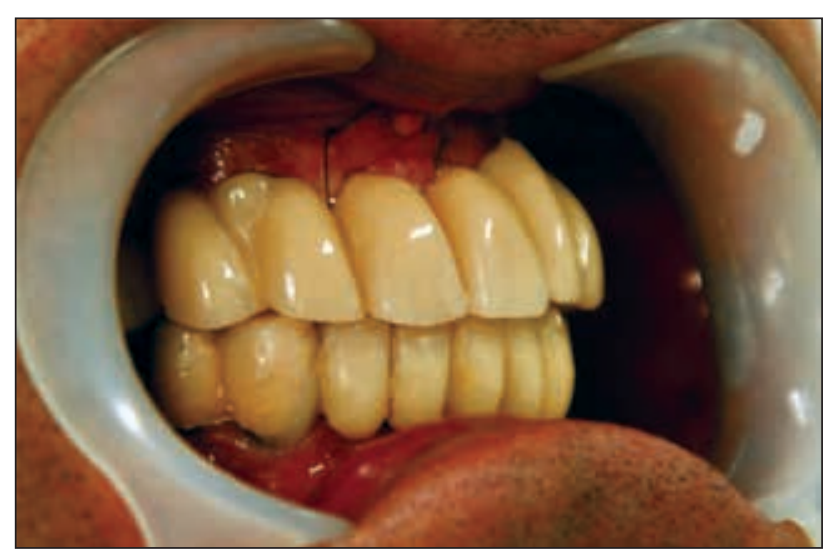

FIGURA 8. Restaurarea protetică provizorie logic, urmând să revină la un interval de 4-5 ore pentru inserarea restaurării provizorii.

După turnarea modelului, s-a realizat în laborator o restaurare provizorie (Fig. 8). În aceeaşi zi, după intervalul mai sus amintit, pacientul s-a prezentat în cabinet, unde s-a realizat fixarea în cavitatea bucală a restaurării provizorii, urmărindu-se conceptul de ,passive fit“ $[15,16]$, folosind fixarea directă a capelor temporare de restaurare cu ajutorul unei răşini autopolimerizabile $\left(\mathrm{Qu}-\right.$ resin $^{\mathrm{TM}}$; Bredent, Senden,Germany).

La 4 luni după momentul inserărării implanturilor, restaurarea provizorie a fost îndepărtată pentru prima dată şi a fost luată o amprentă necesară confecţionării lingurii individuale. $\mathrm{Cu}$ ajutorul acesteia şi al bonturilor de transfer, specifice bonturilor de tip multiunit, a fost amprentat câmpul protetic maxilar cu un amestec de siliconi de adiţie de diferite vâscozităţi Elite HD+ (Zermack) [17] (Fig. 9). De asemenea, au fost determinate şi înregistrate valorile relaţiilor intermaxilare de ocluzie ce au permis montarea într-un articulator total programabil (Artex, Amann Girrbach, Austria) (Fig. 10). 


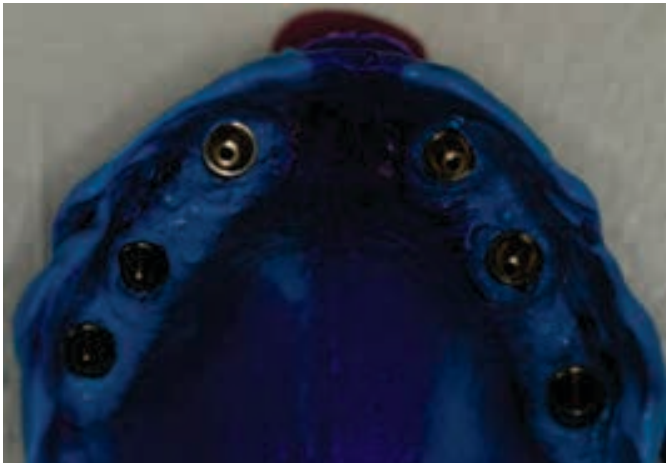

FIGURA 9. Amprentarea câmpului protetic

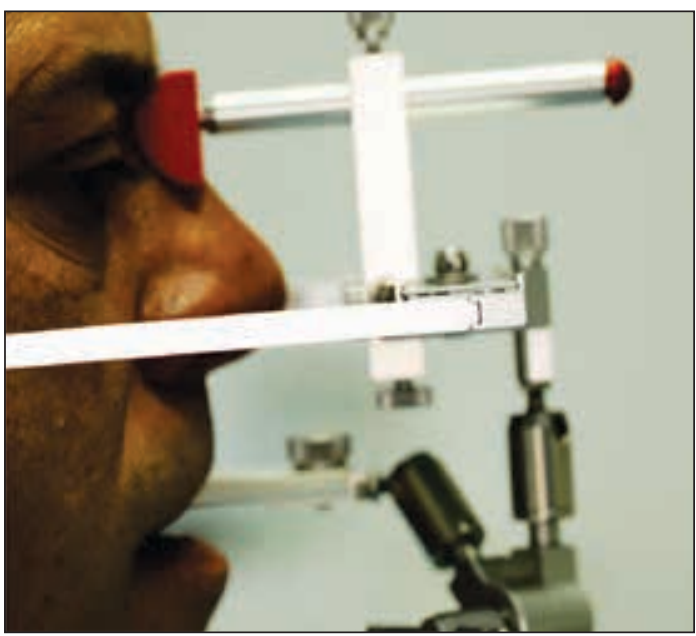

FIGURA 10. Înregistrarea cu arcul facial
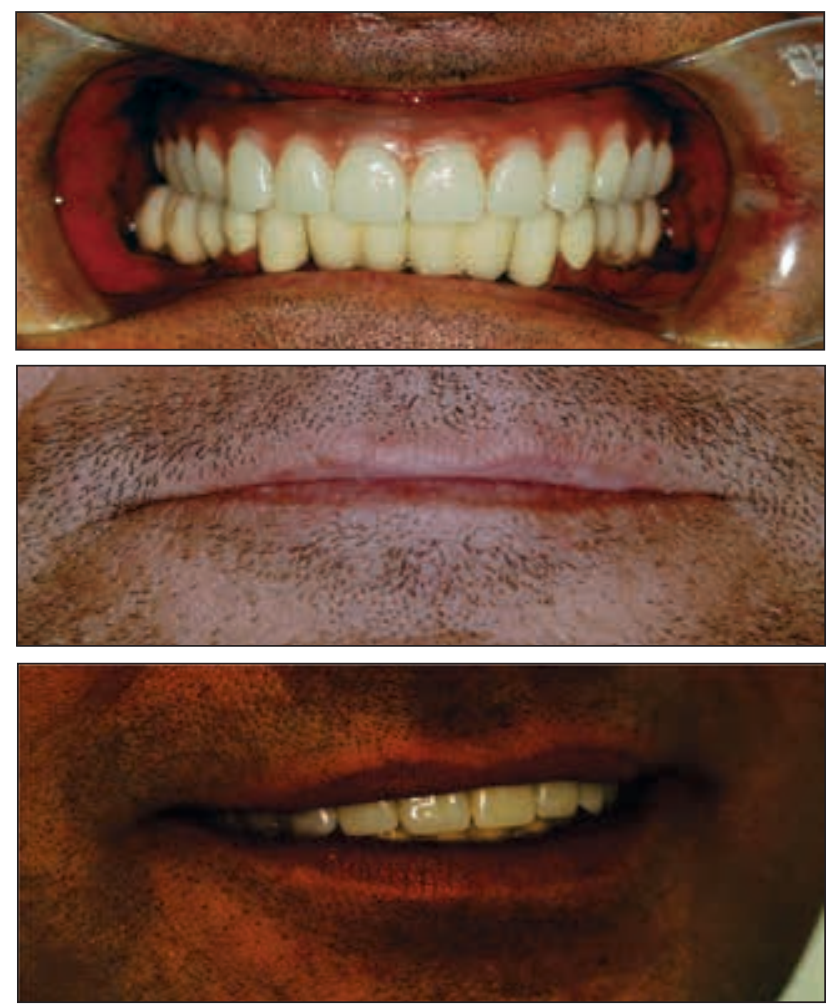

FIGURILE 11, 12, 13. Proba intraorală a machetei şi examinarea extraorală

$\mathrm{Au}$ fost efectuate fazele clinico-tehnice pentru realizarea unei restaurări mixte metalo-acrilice. Pe parcursul acestor etape, a fost urmărit conceptul de „passive fit", redarea dimensiunii verticale de ocluzie, a curburii vestibulare, încercând o reintegrare funcţională şi socială a pacientului cât mai bună (Fig. 11, 12, 13).

Restaurarea protetică finală a fost inserată în cavitatea bucală şi fixată la un torq de $17 \mathrm{Ncm}$. S-au realizat ajustări ocluzale minore în intercuspidare maximă, propulsie şi lateralitate.

Pacientul a fost rechemat la control la o săptămână şi apoi la 30 de zile. De asemenea, a fost efectuată şi o radiografie ortopantomogramă pentru a verifica nivelul osos şi modul corect al inserării restaurării pe implanturi (Fig. 14). Nu au fost reclamate probleme de funcţionalitate sau estetică, pacientul declarându-se mulţumit de confortul obţinut prin intermediul acestei restaurări fixe (Fig. $15,16,17,18)$.

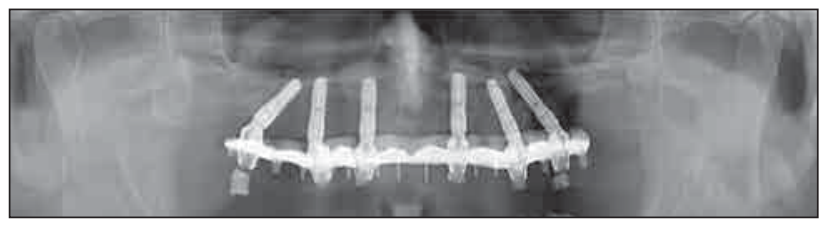

FIGURA 14. Examen radiologic pentru control

\section{DISCUȚII}

Diferitele situaţii clinice, ce presupun trecerea prin stadiul de edentat total în timpul desfăşurării etapelor de tratament, pot să să fie protezate clasic cu ajutorul unei restaurări mobile sau printr-o restaurare fixă cu ajutorul implanturilor dentare. Tipul implanturilor, numărul, topografia acestora determină soluţia de tratament protetic, materialele din care va fi realizată restaurarea şi, nu în ultimul rând, costurile aferente tratamentului. De asemenea, alte 2 concepte ale ultimelor decenii sunt implantarea imediată, postextracţional, dar şi încărcarea imediată a acestora, acestea scurtând foarte mult etapele de tratament. Toate aceste aspecte duc la o reducere considerabilă a timpului de tratament, pacienţii beneficiind mult mai rapid de o reintegrare funcţională, dar şi socială corespunzătoare [18].

Trebuie remarcat şi subliniat faptul că metoda descrisă pe parcursul acestui caz clinic prezintă şi dezavantaje pe care trebuie sa le avem în vedere. Unul dintre principiile conceptului Fast and Fixed (Bredent GmbH, Senden, Germany) îl reprezintă inserţia distală a implanturilor înclinate astfel încât 

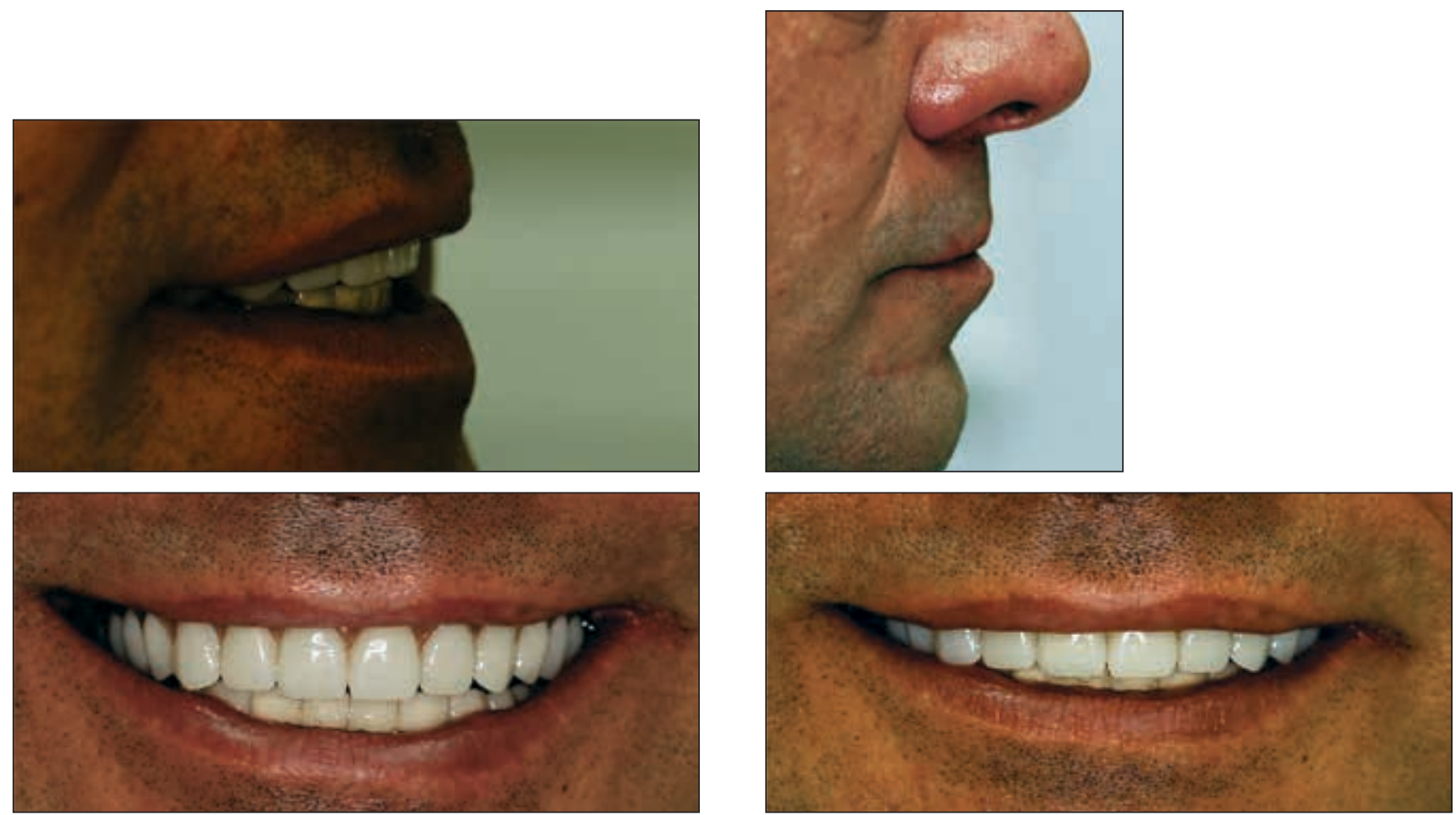

FIGURILE 15, 16, 17, 18. Restaurarea protetică finală. Analiza integrării funcționale şi estetice

să fie ocolite sinusurile maxilare. Rata de succes în această situaţie este ceva mai redusă faţă de cea raportată, de 95\% [19]. Este asemănătoare cu rata de succes în cazul implantării imediat postextracţional [20,21]. Există însă şi contraargumente în această direcţie, care afirmă că nu e o diferenţă considerabilă între inserţia axială sau înclinată a unui implant, ambele având o rată de osteointegrare asemănătoare [22].

Un alt obiectiv important este acela al stabilităţii primare a tuturor implanturilor [14]. Realizarea lui condiţionează încărcarea protetică imediată a acestora.

Restaurarea provizorie deţine un alt rol important în succesul acestei metode terapeutice. Materialele din care este realizată trebuie să ofere stabilitate şi rezistenţă, iar echilibrarea ocluzală în momentul inserţiei pe câmpul protetic necesită o atenţie deosebită. O eventuală deteriorare a acesteia sau chiar o posibilă fractură pot conduce către pierderea implanturilor. În cazul în care implanturile au fost inserate postextracţional, acest aspect legat de stabilitatea ocluzală şi integritatea restaurării protetice provizorii poate fi definitoriu pentru osteointegrare [23].

Acest caz clinic, protezat maxilar cu ajutorul sistemului Fast and Fixed, reprezintă o exemplificare a unei soluţii de tratament pentru situaţiile în care pacientul se găseşte într-o stare premergătoare edentaţiei totale sau este edentat total. Din momentul inserării implanturilor şi până la protezarea fixă definitivă, există însă etape cheie în care, dacă nu sunt sau nu pot fi îndeplinitite criteriile stabilite în protocolul de lucru, întregul flux clinico-tehnic poate fi compromis.

\section{CONCLUZII}

Scopul principal al stomatologiei moderne trebuie să fie obţinerea unei reintegrări funcţionale şi sociale, iar soluţiile de tratament trebuie să fie predictibile, minimum invazive şi, dacă timpul necesar acestora poate fi diminuat, se poate considera că principalele obiective au fost atinse.

Principiile de tratament au cunoscut o continuă îmbunătăţire în ultimele decenii şi, chiar dacă există şi dezavantaje în adoptarea şi aplicarea lor, de fiecare dată când se elaborează un plan de tratament trebuie ca practicienii să ia în considerare toate posibilităţile de realizare.

Această metodă de tratament ce se indică în cazul edentatului total sau al pacientului ce va deveni edentat total permite o reintegrare rapidă a acestuia funcţional şi social, scurtând foarte mult timpii ce trebuie parcurşi clinico-tehnic. Principiul ocolirii formaţiunilor anatomice importante şi al încărcării imediate a implanturilor, cu respectarea condiţiilor de lucru prezentate pe parcursul articolului, vine în 
întâmpinarea acestui deziderat temporal. În acelaşi timp, confortul fiziologic şi psihologic pe care îl obţine pacientul printr-o restaurare protetică fixă recomandă această terapie implantară acolo unde statusul general şi parametrii clinici o permit.

Conflict of interest: none declared

Financial support: none declared

\section{BIBLIOGRAFIE}

1. Felton DA. Complete Edentulism and Comorbid Diseases: An Update. J Prosthodont. 2016 Jan;25(1):5-20.

2. Feine JS, Carlsson GE, Awad MA, Chehade A, Duncan WJ, Gizani $\mathrm{S}$, Head T, et al. The McGill consensus statement on overdentures. Mandibular two-implant overdentures as first choice standard of care for edentulous patients. Montreal, Quebec, May 24-25, 2002. Int J Oral Maxillofac Implants. 2002 Jul-Aug;17(4):601-2.

3. Tyrovolas S, Koyanagi A, Panagiotakos DB, et al. Population prevalence of edentulism and its association with depression and self-rated health. Sci Rep. 2016;6:1-9.3.

4. Emami E, De Souza RF, Kabawat M, Feine JS. The impact of edentulism on oral and general health. Int J Dent. 2013;2013:1-7.

5. https://www.nobelbiocare.com/en-us/all-on-4-treatment-concept.

6. https://www.bredent-implants.com/products-solutions/therapies/ immediate-restoration-therapies/sky-fast-fixed-treatment/.

7. Nelson SJ. Wheeler's Dental Anatomy, Physiology and Occlusion. Elsevier, 2020:239-258.

8. Misch CE. Contemporary Implant Dentistry. 3rd ed. Mosby, 2008.

9. Bedrossian E, Sullivan RM, Fortin Y, Malo P, Indresano T. Fixedprosthetic implant restoration of the edentulous maxilla: a systematic pretreatment evaluation method. J Oral Maxillofac Surg. 2008:66:112-122.

10. Pollini A, Goldberg J, Mitrani R, Morton D. The Lip-Tooth-Ridge Classification: A Guidepost for Edentulous Maxillary Arches. Diagnosis, Risk Assessment, and Implant Treatment Indications. Int J Periodontics Restorative Dent. 2017 Nov/Dec;37(6):835-841.

11. Ahuja $S$, Cagna DR. Classification and management of restorative space in edentulous implant overdenture patients. J Prosthet Dent. 2011 May; 105(5):332-7.

12. Avrampou M, Mericske-Stern R, Blatz MB, Katsoulis J. Virtual implant planning in the edentulous maxilla: criteria for decision making of prosthesis design. Clin Oral Implants Res. 2013 Aug;24 Suppl A100:152-9.

13. Pommer B, Mailath-Pokorny G, Haas R, Busenlechner D, Fürhauser $R$, Watzek $G$. Patients' preferences towards minimally invasive treatment alternatives for implant rehabilitation of edentulous jaws. Eur J Oral Implantol. 2014 Summer;7 Suppl 2:S91-109.

\section{Notă}

Toţi autorii au contribuit în mod egal la realizarea acestui studiu.
14. Papaspyridakos P, Chen CJ, Chuang SK, Weber HP. Implant loading protocols for edentulous patients with fixed prostheses: a systematic review and meta-analysis. Int J Oral Maxillofac Implants. 2014;29 Suppl:256-70.

15. Sahin S, Cehreli MC. The significance of passive framework fit in implant prosthodontics: current status. Implant Dent. 2001; 10(2):85-92.

16. Chen J. The significance and evaluation of precise passive fit of implant restorations, and the application of intraoral welding technology. Zhonghua Kou Qiang Yi Xue Za Zhi. 2020 Nov 9;55(11):825-830.

17. https://www.zhermack.com/public/uploads/F300052_19-07_ Catalogo_STUDIO_EN_low.pdf.

18. Sadowsky SJ, Fitzpatrick B, Curtis DA. Evidence-based criteria for differential treatment planning of implant restorations for the maxillary edentulous patient. J Prosthodont Dent Implant. 2015;23:87-102.

19. Chrcanovic BR, Albrektsson T, Wennerberg A. Tilted versus axially placed dental implants: a meta-analysis. J Dent. 2014;43(2):149-70.

20. Atieh MA, Alsabeeha NH, Payne AG, de Silva RK, Schwass DS, Duncan WJ.The prognostic accuracy of resonance frequency analysis in predicting failure risk of immediately restored implants. Clin Oral Implants Res. 2014;25(1):29-35.

21. Tealdo T, Bevilacqua M, Pera F, Menini M, Ravera G, Drago C, Pera P. Immediate function with fixed implant-supported maxillary dentures: a 12-month pilot study. J Prosthet Dent. 2008 May;99(5):351-60.

22. Del Fabbro M, Ceresoli V. The fate of marginal bone around axial vs. tilted implants: a systematic review. Eur J Oral Implantol. 2014 Summer;7 Suppl 2:S171-89.

23. Wentaschek S, Hartmann S, Walter C, Wagner W. Six-implantsupported immediate fixed rehabilitation of atrophic edentulous maxillae with tilted distal implants. Int J Implant Dent. 2017 Dec;3(1):35. 